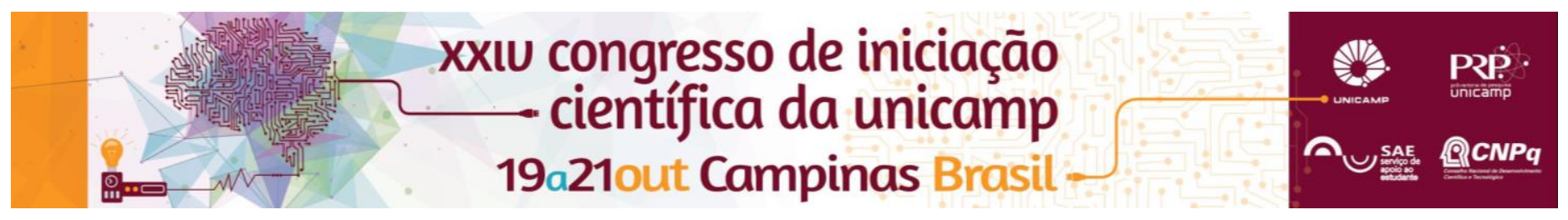

\title{
Atitudes de segurança em um hospital universitário: percepção dos profissionais de enfermagem
}

\author{
Damaris F. P. Alves*, Gisele H. Dorigan, Daniela F.S. Alves, Edinêis B. Guirardello
}

\begin{abstract}
Resumo
A cultura de segurança é avaliada por meio da percepção dos profissionais quanto ao clima de segurança na instituição. Este estudo tem como objetivo avaliar a percepção dos membros da equipe de enfermagem quanto às atitudes de segurança no ambiente de trabalho e verificar se diferem entre as unidades de trabalho. Estudo descritivo de desenho retrospectivo, desenvolvido em um hospital de ensino do interior do Estado de São Paulo. Para coleta de dados utilizou-se o Safety Attitudes Questionnaire - Short form 2006. Participaram 262 profissionais, dos quais 164 $(62,6 \%)$ são técnicos de enfermagem e $98(37,4 \%)$ enfermeiros. A pontuação média para satisfação no trabalho foi de 78,8 e para os domínios trabalho em equipe, percepção do estresse, comportamento seguro e clima de segurança variou entre 60,3 a 69,6 . Foram obtidas médias inferiores a 60 pontos para os domínios percepção da gestão da unidade e gestão do hospital. Não houve diferença entre as unidades de trabalho em relação às atitudes de segurança. Destaca-se que os profissionais possuem uma percepção positiva do clima de segurança apenas para o domínio satisfação no trabalho.
\end{abstract}

Palavras-chave: Segurança do paciente, enfermagem, ambiente de instituições de saúde.

\section{Introdução}

A cultura de segurança nas organizações de saúde pode ser avaliada por meio da percepção dos profissionais quanto ao clima de segurança(1), que é definido como a mensuração das atitudes e da percepção individual das características da cultura de segurança entre os trabalhadores de uma determinada organização(1).

Os objetivos deste estudo foram avaliar a percepção dos profissionais de enfermagem quanto às atitudes de segurança no ambiente de trabalho e verificar se diferem entre as unidades de trabalho.

Estudo de desenho retrospectivo, desenvolvido em um hospital de ensino no interior do Estado de São Paulo. Para coleta de dados utilizou-se o Safety Attitudes Questionnaire (SAQ) - Short form 2006(2), composto por 41 itens distribuídos em sete domínios: clima de trabalho em equipe (6 itens), clima de segurança (7 itens), satisfação no trabalho (5 itens), percepção do estresse (4), percepção da gestão da unidade (6 itens), percepção da gestão do hospital ( 6 itens), condições de trabalho (3 itens) e comportamento seguro (3 itens). A escala de resposta é do tipo Likert de cinco pontos, que varia de discordo totalmente (0 pontos) a concordo totalmente (100 pontos). Pontuações iguais ou superiores a 75 pontos indicam uma percepção positiva do clima de segurança no ambiente de trabalho.

\section{Resultados e Discussão}

Participaram 262 profissionais, sendo 164 técnicos de enfermagem e 98 enfermeiros, sendo $84,0 \%$ do sexo feminino. A maioria é casada $(52,3 \%)$ e possui apenas um vínculo empregatício (80,5\%). Quanto à unidade de trabalho, $84(32,1 \%)$ profissionais são da unidade de terapia intensiva, $147(56,2 \%)$ de unidade de internação adulto e $31(11,9 \%)$ do serviço de pediatria.

Os profissionais avaliaram positivamente apenas 0 domínio satisfação no trabalho. Os domínios com as DOI: 10.19146/pibic-2016-51036 menores pontuações médias foram relacionados à percepção da gestão da unidade e da gestão do hospital (Tabela 1). Destaca-se que a percepção desses profissionais quanto às atitudes de segurança não difere entre as unidades de trabalho.

Tabela 1. Descrição da percepção dos profissionais sobre os domínios do Safety Attitude Questionnaire (SAQ). Campinas,SP, Brasil, 2016.

\begin{tabular}{lccc}
\hline Domínios SAQ & Média & $\begin{array}{c}\text { Desvio } \\
\text { Padrão }\end{array}$ & Mediana \\
\hline Satisfação trabalho & 78,8 & 19,1 & 85,0 \\
Trabalho em equipe & 69,6 & 17,9 & 70,8 \\
Percepção do estresse & 69,3 & 27,1 & 75,0 \\
Comportamento & & & \\
seguro & 66,6 & 23,9 & 75,0 \\
Clima de segurança & 63,1 & 18,0 & 67,9 \\
Condições trabalho & 60,3 & 25,8 & 58,3 \\
$\begin{array}{l}\text { Percepção gestão } \\
\text { unidade }\end{array}$ & 55,7 & 21,7 & 58,3 \\
Percepção gestão & & & 50,0 \\
hospital & 50,5 & 20,4 & \\
\hline
\end{tabular}

\section{Conclusões}

Os profissionais possuem uma percepção positiva em relação à segurança apenas para o domínio satisfação no trabalho. Destaca-se que os domínios gestão da unidade de gestão do hospital foram os que obtiveram as menores pontuações médias e apontam uma percepção desfavorável quanto às atitudes de segurança.

${ }^{1}$ Singer SJ, Gaba DM, Falwell A, Lin S, Hayes J, Baker L. Patient Safety Climate in 92 US Hospitals: differences by work area and discipline. Med Care 2009; 47:23-31.

${ }^{2}$ Carvalho RE, Cassiani SHB. Cross-cultural adaptation of the Safety Attitudes Questionnaire - Short Form 2006 for Brazil. Rev Lat Am Enfermagem. 2012;20(3):575-82. 